\title{
Alcohol, Tobacco and Tramadol Daily Consumption and Road Traffic Crashes among Motorcycle Taxi Drivers in Cotonou (Benin)
}

\author{
Ghislain Emmanuel Sopoh1, Akouété Nicolas Gaffan², Charles Sossa-Jérôme², \\ Alphonse Kpozèhouen², Yolaine Glèlè-Ahanhanzo² \\ ${ }^{1}$ Health and Environment Department, Regional Institute of Public Health, Ouidah, Benin \\ ${ }^{2}$ Multidisciplinary Research Unity for Road Crashes Prevention (ReMPARt), Department of Epidemiology and Bio-statistics, \\ Regional Institute of Public Health, University of Abomey-Calavi, Ouidah, Benin \\ ${ }^{3}$ Department of Health Promotion, Regional Institute of Public Health, University of Abomey-Calavi, Ouidah, Benin \\ Email: ghislainsop@yahoo.fr
}

How to cite this paper: Sopoh, G.E., Gaffan, A.N., Sossa-Jérôme, C., Kpozèhouen, A. and Glèlè-Ahanhanzo, Y. (2021) Alcohol, Tobacco and Tramadol Daily Consumption and Road Traffic Crashes among Motorcycle Taxi Drivers in Cotonou (Benin). Open Journal of Epidemiology, 11, 433-445.

https://doi.org/10.4236/ojepi.2021.114035

Received: September 30, 2021

Accepted: November 7, 2021

Published: November 10, 2021

Copyright $\odot 2021$ by author(s) and Scientific Research Publishing Inc. This work is licensed under the Creative Commons Attribution International License (CC BY 4.0).

http://creativecommons.org/licenses/by/4.0/

(c) (i) Open Access

\begin{abstract}
Background: In Benin, motorcycle taxi drivers make up a significant portion of road transport. The use of psychoactive substances, a behavior recognized as being at risk of road crashes, is frequent in this group. This study aimed to analyze the association between the consumption of psychoactive substances and the occurrence of road crashes among motorcycle taxi drivers. Methods: This was a cross-sectional study involving 430 motorcycle taxi drivers selected from motorcycle taxi stands in Cotonou (Benin) using a twostage cluster sampling technique. An interview with a structured questionnaire was used to collect data, which took place in March and April 2019. Alcohol, tramadol, and tobacco were the psychoactive substances considered in this study and their daily use was investigated. A binary logistic regression was used for the analysis. Results: Among the motorcycle taxi drivers surveyed, $27.79 \%(95 \% \mathrm{CI}=23.71-32.25)$ were involved in a road crash. The prevalence of psychoactive substances daily use was: $30.41 \%(95 \% \mathrm{CI}=26.17$ 35.00 ) for alcohol, $28.50 \%$ ( $95 \% \mathrm{CI}=24.37$ - 33.02) for tramadol and $4.03 \%$ $(95 \% \mathrm{CI}=2.51-6.42)$ for tobacco. Alcohol daily consumption $(\mathrm{AOR}=2.09$, $95 \% \mathrm{CI}=1.27-3.45, \mathrm{p}=0.004)$ was associated with a significant risk of road crashes. Conclusion: Interventions aiming to reduce psychoactive substances use should, therefore, be included in road safety policies, especially for this group.
\end{abstract}

\section{Keywords}

Road Crash, Psychoactive Agent, Health at Work, Benin 


\section{Introduction}

Each year, 1.35 million people die on roads around the world and millions more are disabled as a result of Road Crashes (RC) [1]. The risk of road traffic deaths varies significantly by region [1]. Europe has a road traffic fatality rate below the global average while the highest rates are in Africa [1]. Road traffic deaths are particularly high in this region because road transport is dominated by motorized two-wheelers who are particularly vulnerable road users. It is estimated that per vehicle mile (1.609 kilometers) travelled, motorcyclists are 35 times more likely than passenger car occupants to die in a motor vehicle traffic crash and 8 times more likely to be injured [2].

Like several African countries, Benin's road transport is characterized by a predominance of two-wheeled vehicles users and low development of public transport services [3]. This situation has favored the emergence of motorcycle taxis (a mode of public transport of people and/or goods by using motorcycles) which today represents $75 \%$ of transport services in Cotonou (economic capital of Benin) [4]. In addition, according to a study, there are 10,610 new Motorcycle Taxi Drivers (MTDs) each year in Cotonou [5]. Despite the importance of these professionals, this activity is not sufficiently regulated, with neither knowledge of road traffic rules nor a license/authorization to drive motorcycle taxis being required. This situation contributes to increasing the risk for MTDs themselves and their passengers to be exposed to RCs. Several studies confirm that RCs are one of the main risks to which MTDs are exposed. A prevalence of RCs ranging from $27 \%$ to $68 \%$ in this population has been reported in the scientific literature [6] [7] [8] [9] [10]. Besides, a study in 2016 highlighted a case fatality rate of $5.2 \%$ of RCs among MTDs [11].

Among factors that may explain RCs among MTDs, driving under the influence of psychoactive substances (alcohol, tobacco, and drugs) may play a major role. Indeed, a significant proportion of MTDs uses some forms of psychotropic drugs to combat fatigue resulting from long working hours. Tramadol use is poorly documented, but nowadays it tends to be the most common psychoactive substance taken in [12]. In Benin, the prevalence of tramadol addiction among MTDs was 45\% [13]. Alcohol consumption, on the other hand, continues to be a common behavior among MTDs, with a prevalence ranging from $29.5 \%$ to $69 \%$ [7] [8] [10] [14]. The results of a study in Nigeria showed that tobacco consumption was significantly higher than that reported for other drugs such as cannabis [15]. By the way, hypotheses have been put forward as to the neurological and/or physiological effects of toxic substances in tobacco that interfere with driving [16].

Studies in some African countries have shown an association between alcohol consumption and the occurrence of an RC among MTDs [7] [14]. The existence of a potential association between tramadol or tobacco consumption and the occurrence of an RC is yet to be documented.

Thus, in order to contribute to the fight against psychoactive substances and 
road safety, this study aims to analyze the association between the consumption of psychoactive substances (alcohol, tobacco, and tramadol) and the occurrence of an RC among MTDs in Cotonou.

\section{Materials and Methods}

\subsection{Study Design, Population, and Sampling}

This was a cross-sectional study whose data collection period extended from 25 March to 19 April 2019 in Cotonou.

A probabilistic method and a two-stage cluster sampling technique were applied to select MTDs that were included in the study. The minimum sample size calculated according to the Schwartz formula [17] with an expected frequency of $27 \%$ suggested by the literature [10], a confidence level of $95 \%$, an acceptable margin of error of $6 \%$ and a design effect of two was 420 MTDs. The primary units were motorcycle taxi stands. Thus, 30 clusters corresponding to motorcycle taxi stands were selected. The secondary units were MTDs registered at the selected stands. Number of MTD to select per stand was estimated using a proportionality rate per stand (Proportionality rate per stand = Number of MTD per stand/total number of stands selected), taking into account the fact that the number of MTD varies per stand. Within the stand, MTD were randomly selected using voucher. Individuals who had been working as MTDs for less than three months and those who had not given free written consent to participate in the study were not included.

\subsection{Variables and Measures}

The main outcome variable considered was the occurrence of an RC. It was informed by a binary declaration by each MTD: "Yes", if an MTD has been the victim of at least one RC during their job as an MTD and "No" if not. For this study, an RC was considered a collision that occurred on the road, within or outside of Cotonou, before the day on which the data collector questioned the MTD, between the MTD while working and any other thing or person and that causes injuries to them.

The key exposure was the consumption of psychoactive substances. Specifically, alcohol, tobacco, and Tramadol were considered. The use (or non-use) of alcohol, tobacco and Tramadol was assessed using an adapted version of the Alcohol, Smoking and Substance Involvement Screening Test (ASSIST) [18]. In particular, we relied on the first two questions of this tool. In accordance with the ASSIST, a first question (In your life, which of the following substances have you ever used?) asked about past use of alcohol, tobacco, and tramadol, and a second question (How often have you used the substances you mentioned?) was designed to measure the frequency of use of the psychoactive substances included in this study [18]. However, unlike the ASSIST where the frequency of substance use is assessed over the past three months, in this study the frequency of use in the 30 days ( 1 month) before the day of the interviewer's visit was meas- 
ured [18]. Based on the ASSIST questionnaire, the possible responses to the frequency of use of the substances studied were "Never", "Once or Twice", "Monthly", "Weekly (1 - 2 times a week)", "daily or almost daily (>3 times a week)". These modalities have been split in 2 categories (from "Never" to "weekly")/“daily or almost daily".

In the end, the consumption of these substances was categorized into two modalities based on frequency and furthermore on regularity of consumption:

- No = if an MTD declared not to use the substances studied and or if its frequency of consumption is less than "daily or almost daily";

- Yes = if an MTD reported that its frequency of consumption is "daily or almost daily";

The other variables retained were:

- Socio-demographic variables: age (years), gender (male/female), marital status (single or living alone/married or living in a couple) and level of education (none/primary and higher);

- Profession-related variables: number of years of riding (0 to 10 years/11 years and more), type of MTD (regular/occasional), daily income (Less than 8.9 USD/8.9 USD or more) and RC history before becoming an MTD (yes/no).

\subsection{Data Analysis}

This questionnaire used in this study was administered by interviewers who had been trained beforehand. It was previously tested on a few MTDs who were selected at stands but not included in the study. This test made it possible to assess the acceptability and comprehension of the questionnaire and to reviews the tool. Data were entered with Epi Info 7.2 and analyzed with Stata/SE 15.1. Data analysis consisted of calculating weighted percentages for qualitative variables, weighted means and standard deviations for quantitative variables with a normal distribution. The median and the Interquartile Range (IQR) were determined for quantitative variables where the distribution was not normal. A multivariate binary logistic regression was used to identify predictors of RCs. In the multivariate analysis, only variables with $\mathrm{p}<0.20$ in univariate analysis were introduced into a backward stepwise model to obtain adjusted estimates. The results were presented as odds ratios (OR) with their 95\% confidence interval (95\% CI). The level of statistical significance was set at $\mathrm{p}<0.05$. A Hosmer-Lemeshow goodness-of-fit test was used to ensure the adequacy of the model.

\subsection{Ethical Statement}

The study protocol was approved by the internal institutional ethical review board of the Regional Institute of Public Health. Administrative authorizations were obtained before data collection. Ethical standards in research have been taken into account. Participants received a detailed briefing note. Data collected from participants were anonymous and confidential. They were collected individually after obtaining the written and informed consent of each participant. 


\section{Results}

A total of 430 MTDs were included in the study. Table 1 shows characteristics of the participants. The median age of MTDs surveyed was 38 years $(\mathrm{IQR}=32-45)$

Table 1. Characteristics of MTDs in Cotonou (Benin), 2019.

\begin{tabular}{|c|c|c|c|}
\hline Variables & Median (IQR**) & Frequency & $\begin{array}{l}\text { Weighted } \\
\text { percentages }\end{array}$ \\
\hline Age (years) $(n=426)$ & $38(32-45)$ & & \\
\hline \multicolumn{4}{|l|}{ Gender $(n=430)$} \\
\hline Male & & 430 & 100 \\
\hline \multicolumn{4}{|l|}{ Marital status $(\mathrm{n}=428)$} \\
\hline Married or living in a couple & & 395 & 92.29 \\
\hline Single or living alone & & 33 & 7.71 \\
\hline \multicolumn{4}{|l|}{ Level of education $(\mathrm{n}=428)$} \\
\hline None & & 135 & 31.37 \\
\hline Primary or higher & & 293 & 68.63 \\
\hline \multicolumn{4}{|l|}{ Type of driver $(n=428)$} \\
\hline Occasional & & 96 & 22.71 \\
\hline Regular & & 332 & 77.29 \\
\hline \multicolumn{4}{|l|}{ Daily income (USD) $(\mathrm{n}=401)$} \\
\hline Less than 8.9 & & 363 & 90.56 \\
\hline 8.9 and more & & 38 & 9.44 \\
\hline \multicolumn{4}{|l|}{ Number of years of riding $(\mathrm{n}=428)$} \\
\hline $0-10$ & & 303 & 70.62 \\
\hline 11 or more & & 125 & 29.38 \\
\hline RC history $(\mathrm{n}=424)$ & & 126 & 30.27 \\
\hline Yes & & 298 & 69.73 \\
\hline No & & & \\
\hline \multicolumn{4}{|l|}{ Alcohol daily consumption $(\mathrm{n}=421)$} \\
\hline Yes & & 128 & 30.41 \\
\hline No & & 293 & 69.59 \\
\hline \multicolumn{4}{|c|}{ Tobacco daily consumption $(n=423)$} \\
\hline Yes & & 17 & 4.03 \\
\hline No & & 406 & 95.97 \\
\hline \multicolumn{4}{|c|}{ Tramadol daily consumption $(\mathrm{n}=420)$} \\
\hline Yes & & 121 & 28.50 \\
\hline No & & 299 & 71.50 \\
\hline
\end{tabular}


and all participants were males. They were mainly in a couple (92.29\%) and had a primary or higher level of education (68.63\%). Nearly eight out of ten participants had no other job alongside their job as an MTD. The majority of MTDs surveyed $(70.62 \%)$ had a number of years of riding less than 11 years. About $90 \%$ of participants earned on average less than 8.9 USD francs per day. Among participants, $27.79 \%(95 \% \mathrm{CI}=23.71-32.25)$ have already been victims of an RC.

Among the MTDs surveyed, 30.41\% (95\% CI = 26.17 - 35.00) reported alcohol daily consumption. The prevalence of tramadol daily use was $28.50 \%(95 \% \mathrm{CI}=$ 24.37 - 33.02) and that of tobacco daily consumption was $4.03 \%$ (95\% CI $=2.51$ 6.42). In addition, an association was observed between alcohol and tobacco consumption $(\mathrm{p}<0.001)$. Following the univariate and multivariate analysis (Table 2 ), alcohol consumption was associated with the occurrence of an RC among MTDs adjusted for daily income, number of years of riding and RC history. MTDs who reported alcohol use were $2.09(95 \% \mathrm{CI}=1.27-3.45, \mathrm{p}=0.004)$ times more likely to be a victim of an RC with equal daily income, number of years of riding and RC history. Tobacco ( $\mathrm{UOR}=1.21,95 \% \mathrm{CI}=0.41-3.58, \mathrm{p}=0.718$ ) or Tramadol $(\mathrm{UOR}=1.55,95 \% \mathrm{CI}=0.97-2.47, \mathrm{p}=0.063)$ daily consumption was not significantly associated with RCs among MTDs in the univariate analysis and was not included in the multivariate analysis.

Other factors significantly associated with RCs were a daily income of USD 8.9 and more $(\mathrm{AOR}=2.08,95 \% \mathrm{CI}=1.05-4.11, \mathrm{p}=0.034), 11$ years of riding and more $(\mathrm{AOR}=2.01,95 \% \mathrm{CI}=1.20-3.38, \mathrm{p}=0.008)$ and a RC history (AOR $=2.74,95 \% \mathrm{CI}=1.66-4.52, \mathrm{p}<0.001)$.

According to the Hosmer-Lemeshow test, the final model fits a set of the observations $(\mathrm{p}=0.936)$.

\section{Discussion}

This study determined the prevalence of psychoactive substances use among MTDs and identified alcohol daily consumption as a factor associated with the occurrence of RCs in this group.

The prevalence of alcohol daily consumption was about $30 \%$. Our results also suggest that alcohol daily consumption is a significant predictor of the risk of RCs among MTDs. This could be explained by the fact that MTDs who reported alcohol use are those who tend to drive with high blood alcohol concentration, increasing their risk of being a victim of an RC. In fact, the profession of MTD is a social phenomenon that appeared in Benin in the 1980s, following a major economic crisis that generated many job losses. This profession, which has been organized over the years into a real professional corporation, is most often carried out by unemployed graduates, in search of daily gain. The latter often work more than 8 hours a day, at late hours, in order to be able to earn the minimum necessary to live. As a result, many, among them, are forced to consume alcohol or other psychoactive substances to be able to support the daily rhythm of work. As for driving under the influence, there is an increased risk of an RC as soon as 
Table 2. Factors associated with RCs among MTDs in Cotonou, 2019.

\begin{tabular}{|c|c|c|c|c|c|c|}
\hline \multirow{2}{*}{ Variables } & \multicolumn{3}{|c|}{ Univariate analysis } & \multicolumn{3}{|c|}{ Multivariate analysis } \\
\hline & $\mathrm{UOR}^{\mathrm{a}}$ & $95 \% \mathrm{CI}^{\mathrm{b}}$ & p-value & $\mathrm{AOR}^{\mathrm{c}}$ & $95 \% \mathrm{CI}$ & p-value \\
\hline Age (years) $(n=426)$ & 1.01 & $0.98-1.03$ & 0.348 & & & \\
\hline \multicolumn{7}{|l|}{ Marital status $(n=428)$} \\
\hline Married or living in a couple & 1.40 & $0.59-3.34$ & 0.441 & & & \\
\hline Single or living alone & 1.00 & & & & & \\
\hline \multicolumn{7}{|l|}{ Level of education $(n=428)$} \\
\hline None & 1.21 & $0.77-1.91$ & 0.393 & & & \\
\hline Primary or higher & 1.00 & & & & & \\
\hline \multicolumn{7}{|l|}{ Type of driver $(\mathrm{n}=428)$} \\
\hline Occasional & 1.00 & & & & & \\
\hline Regular & 1.50 & $0.86-2.60$ & 0.148 & & & \\
\hline \multicolumn{7}{|l|}{ Daily income (USD) $(\mathrm{n}=401)$} \\
\hline Less than 8.9 & 1.00 & & & 1.00 & & \\
\hline 8.9 and more & 1.77 & $0.87-3.59$ & 0.111 & 2.08 & $1.05-4.11$ & 0.034 \\
\hline \multicolumn{7}{|l|}{ Number of years of riding $(n=428)$} \\
\hline $0-10$ & 1.00 & & & 1.00 & & \\
\hline 11 or more & 2.13 & $1.35-3.35$ & 0.001 & 2.01 & $1.20-3.38$ & 0.008 \\
\hline \multicolumn{7}{|l|}{ RC history $(\mathrm{n}=424)$} \\
\hline Yes & 2.95 & $1.88-4.65$ & $<0.001$ & 2.74 & $1.66-4.52$ & $<0.001$ \\
\hline No & 1.00 & & & 1.00 & & \\
\hline \multicolumn{7}{|l|}{ Alcohol daily consumption $(\mathrm{n}=421)$} \\
\hline Yes & 2.16 & $1.37-3.40$ & 0.001 & 2.09 & $1.27-3.45$ & 0.004 \\
\hline No & 1.00 & & & 1.00 & & \\
\hline \multicolumn{7}{|c|}{ Tobacco daily consumption $(\mathrm{n}=423)$} \\
\hline Yes & 1.21 & $0.41-3.58$ & 0.718 & & & \\
\hline No & 1.00 & & & & & \\
\hline \multicolumn{7}{|c|}{ Tramadol daily consumption $(\mathrm{n}=420)$} \\
\hline Yes & 1.55 & $0.97-2.47$ & 0.063 & & & \\
\hline No & 1.00 & & & & & \\
\hline
\end{tabular}

a95\% confidence interval; ${ }^{\mathrm{b}}$ Adjusted Odds Ratio; ' Unadjusted Odds Ratio.

there is even a low blood alcohol level, and this risk increases significantly when the level is greater than or equal to $0.04 \mathrm{~g} / \mathrm{dL}$ [19]. Alcohol affected drivers in many aspects including attitude, judgment, vigilance, perception, reaction, and control of the vehicle [20]. Ofonime et al. in 2012 also observed an association 
between alcohol consumption and the occurrence of an RC among MTDs $\left(\chi^{2}=\right.$ $31.5, \mathrm{p}<0.001$ ) [7]. A matched case-control study conducted in Uganda in 2016 indicated that MTDs who reported alcohol consumption were $2.30(95 \% \mathrm{CI}=$ $1.19-4.45, \mathrm{p}=0.004)$ times more likely to be a victim of an RC [14]. According to the World Health Organization (WHO), the adoption and enforcement of legislation on the main behavioral risk factors of RCs are essential elements of an integrated strategy to prevent deaths due to RCs [1]. As part of the fight against drink-driving, the WHO proposes setting a blood alcohol concentration at 0.05 $\mathrm{g} / \mathrm{dL}$ for the general population and $0.02 \mathrm{~g} / \mathrm{dL}$ for young and inexperienced drivers [1]. Benin has a national drink-driving law with a blood alcohol concentration of $0.05 \mathrm{~g} / \mathrm{dL}$ in accordance with the WHO recommendations, but its effective implementation is still limited by the availability of resources and various other considerations such as the training of monitoring units. An integrated approach is recommended for the application of these regulations with a combination of awareness and police monitoring [1].

The prevalence of tramadol daily use was $28.50 \%$. This frequency is lower than that obtained by Djidonou et al. in 2015 [13]. The use of an adapted version of the ASSIST in our study could explain this difference. Thus, an under-reporting cannot be ruled out in our study. MTDs who use this product are more likely to be victims of RCs than those who do not, although this risk is not significant. Further studies should be carried out to confirm this. In this study, reasons, why MTDs use psychoactive substances, was not explored. According to Djidonou et al., the reasons of tramadol use were to seek performance while riding, to overcome fear, to seek endurance while riding, to seek pleasure and group membership and companionship [13]. This indicates the areas of intervention that communications should target for behavior change while emphasizing the long-term health risks associated with the use of this substance. The success of these campaigns is only possible if they are combined with effective enforcement of laws on driving under the influence of psychoactive substances.

About $4 \%$ of the subjects studied reported smoking. In univariate analysis, consumption was associated with a higher (no significant) risk of RCs. The observed association between alcohol and tobacco confirms the relevance of integrating interventions to prevent the use of these two products for greater effectiveness. Further research on the relationship between smoking and the occurrence of an RC is needed.

The main limitation of this work was that it was a cross-sectional study. This meant that the temporal relationship cannot be established between the exposure factors and the main outcome. In addition, questions about risk behaviors for RCs are likely to be subject to information bias leading to a possible underestimation of their prevalence. Not using the full version of the ASSIST is also a limitation of this study. Only the MTDs registered at the motorcycle taxi stands in Cotonou were included. Although they represent $80 \%$ of the MTDs working in Cotonou, selection bias cannot be entirely ruled out and caution is needed in 
extrapolating results [21]. Finally, because of inclusion criteria, MTDs that died as a result of an RC were not taken into account. This could lead to an underestimation of the frequency of RCs that was observed.

\section{Conclusion}

Following this investigation, alcohol consumption is a risk factor for the occurrence of RCs, which affects not only the health of MTDs themselves but also that of their passengers. This confirms the importance of stepping up awareness campaigns for behavioral change towards a reduction in the frequency of alcohol consumption among this population. These interventions will be more effective if they are integrated into road safety strategies. Regarding to the research component, studies to identify determinants of psychoactive substances use will make it possible to adapt strategies and evaluative research on the application of laws relating to driving under the influence.

\section{Acknowledgements}

The authors' gratitude goes to the data collectors and all respondents for their willingness to participate in the study.

\section{Conflicts of Interest}

The authors declare no conflicts of interest.

\section{References}

[1] World Health Organization (2018) Global Status Report on Road Safety 2018. World Health Organization, Geneva.

https://apps.who.int/iris/bitstream/handle/10665/276462/9789241565684-eng.pdf?u $\underline{\mathrm{a}=1}$

[2] National Highway Traffic Safety Administration (2008) Traffic Safety Facts 2007. National Highway Traffic Safety Administration, Washington DC. https://crashstats.nhtsa.dot.gov/Api/Public/ViewPublication/811002

[3] Ministère des Infrastructures et des Transports (2017) Annuaire des Statistiques 2013-2016.

https://transports.bj/wp-content/uploads/2018/03/Annuaire Statistique TPT 2013 2016 VF.pdf

[4] Djossou, G.N. (2016) Analyse des risques et des déterminants du choix de lactivité de taxi-moto à Cotonou (Bénin).

[5] Mama, D., Dimon, B., Aina, M., Adounkpe, J., Ahomadegbe, M., Youssao, A., et al. (2013) Transport urbain au Benin et pollution atmosphérique: évaluation quantitative de certains polluants chimiques de Cotonou. International Journal of Biological and Chemical Sciences, 7, 377-386.

[6] Nguyen, T., Vissoci, J.R.N., Joelson, T., Pesambili, M., Haglund, M., Gerardo, C.J., et al. (2018) Injury Prevalence and Safety Habits of Boda Boda Drivers in Moshi, Tanzania: A Mixed Methods Study. PLoS ONE, 13, Article ID: e0207570. https://doi.org/10.1371/journal.pone.0207570

[7] Ofonime, E.J. (2012) Prevalence and Pattern of Road Traffic Accidents among Com- 
mercial Motorcyclists in a City in Southern Nigeria. Educational Research, 3, 537-542.

[8] Silva, D.W., Andrade, S.M., Soares, D.F.P.P., Mathias, T.A., Matsuo, T. and Souza, R.K. (2012) Factors Associated with Road Accidents among Brazilian Motorcycle Couriers. The Scientific World Journal, 2012, Article ID: 605480. https://doi.org/10.1100/2012/605480

[9] Almeida, G.C.M., Medeiros, F.C.D., Pinto, L.O., Oliveira, J.M.B. and Lima, K.C. (2016) Prevalence and Factors Associated with Traffic Accidents Involving Motorcycle Taxis. Revista Brasileira de Enfermagem, 69, 359-365. https://doi.org/10.1590/0034-7167.2016690223i

[10] Owino, J.O. (2018) Factors Associated with Accidents Involving Commercial Motorcyclists in Migori Town, Kenya. International Journal of Research and Innovation in Social Science, 2, 57-67.

[11] Madougou, S., Chigblo, P.S., Tchomtchoua, A.S., Lawson, E., Yetognon, L. and Akue, A.H.-M. (2016) Incidence et impacts des accidents de la voie publique chez les conducteurs de taxi-moto en milieu tropical. Revue de Chirurgie Orthopédique et Traumatologique, 102, 211-214. https://doi.org/10.1016/j.rcot.2016.01.005

[12] Maiga, D.D., Seyni, H., Moussa, A.O. and Sidikou, A. (2012) Mesusage du Tramadol par les adolescents et jeunes adultes en situation de rue. The Pan African Medical Journal, 13, Article No. 55.

[13] Djidonou, A., Tognon-Tchégnonsi, F., Gansou, G., et al. (2015) Prévalence et facteurs associés à l'addiction au Tramadol chez les conducteurs de taxi-moto (Zé) à Parakou/Bénin. Le Bénin Médical, 60, 7-13.

[14] Tumwesigye, N.M., Atuyambe, L.M. and Kobusingye, O.K. (2016) Factors Associated with Injuries among Commercial Motorcyclists: Evidence from a Matched Case Control Study in Kampala City, Uganda. PLoS ONE, 11, Article ID: e0148511. https://doi.org/10.1371/journal.pone.0148511

[15] Gudaji, M.I. and Habib, Z.G. (2016) Prevalence of Psychoactive Substance Use among Registered Commerceal Motorcycle Operators in Kano, North Western Nigeria: A community Study. International Journal of Mathematics and Mathematical Sciences, 8, 105-111. https://doi.org/10.5897/IJMMS2015.1207

[16] Pederson, L.L., Koval, J., Vingilis, E., Seeley, J., Ialomiteanu, A.R., Wickens, C.M., et al. (2018) The Relationship between Motor Vehicle Collisions and Cigarette Smoking in Ontario: Analysis of CAMH Survey Data from 2002 to 2016. Preventive Medicine Reports, 13, 327-331. https://doi.org/10.1016/j.pmedr.2018.12.013

[17] Schwartz, D. (1996) Méthodes statistiques à l'usage des médecins et biologistes. 4ème edition. Médecines Sciences Flammarion, Paris, 314 p.

[18] Humeniuk, R. and World Health Organization (2010) The Alcohol, Smoking and Substance Involvement Screening Test (ASSIST): Manual for Use in Primary Care. World Health Organization, Geneva.

[19] World Health Organization (2021) Principaux repères sur les accidents de la route. https://www.who.int/fr/news-room/fact-sheets/detail/road-traffic-injuries

[20] Zhao, X., Zhang, X. and Rong, J. (2014) Study of the Effects of Alcohol on Drivers and Driving Performance on Straight Road. Mathematical Problems in Engineering, 2014, Article ID: 607652. https://doi.org/10.1155/2014/607652

[21] Marchais, G. (2009) Règles publiques, règles privées: Les taxis-motos au Bénin. L'Economie politique, 41, 59-68. https://doi.org/10.3917/leco.041.0059 


\section{Alcohol, Tobacco and Tramadol Daily Consumption and Road Traffic Crashes among Motorcycle Taxi Drivers in Cotonou (Benin)}

\section{Consent Form}

My name is , research assistant in a study that aims to analyze the association between the consumption of psychoactive substances (alcohol, tobacco, and Tramadol) and road crashes among motorcycle taxi drivers in Cotonou.

According to statistics, two people die every day as a result of road crashes in Benin. Thus, given the magnitude and gravity of road crashes in Benin and Cotonou in particular, efforts are needed to make roads safer. This is the purpose of this study, which specifically targets motorbike-taxi drivers. According to several studies in Africa, between 27 and $68 \%$ of motorcycle taxi drivers are victims of road crashes. Among factors that may explain road crashes among these road users, driving under the influence of psychoactive substances (alcohol, tobacco, and drugs) play a role that should not be neglected. Thus, to contribute to the fight against psychoactive substances and road safety, this study aims to measure the level of psychoactive substances use, determine the frequency of road crashes, and study the relationship between psychoactive substances use and road crashes among motorcycle taxi drivers.

To do this, we need your participation. Your decision to participate in this study is entirely voluntary. If you agree, you will be asked to complete a questionnaire on your demographic and occupational characteristics and behaviours. The interview will last about five minutes. Data we collect from this study will be confidential and will only be used for this study.

If you have any questions or clarifications about the study, please do not hesitate to ask:

1. Are you registered on a motorbike-taxi stand?

Yes $\square$

No $\square$

2. Have you understood the information given above?

Yes $\square$

No $\square$

3. Do you agree to participate in the study?

Yes

No $\square$

Signature or fingerprint 


\begin{tabular}{|c|c|c|c|}
\hline ID & |_ll___ & Date & $|+||-| \quad \mid$ \\
\hline Code of the interviewer & |_||_||_| & Code of the stand & |_I_-__ \\
\hline
\end{tabular}

\begin{tabular}{|c|c|c|c|}
\hline $\mathbf{N}^{\bullet}$ & Questions & Responses & \\
\hline Q1 & How old are you? & $\mid$ & \\
\hline Q2 & Gender & $\begin{array}{l}\text { 1. Male } \\
\text { 2. Female }\end{array}$ & $\begin{array}{l}\square \\
\square\end{array}$ \\
\hline Q3 & What is your current marital status? & $\begin{array}{l}\text { 1. Married or living in a couple } \\
\text { 2. Single or living alone }\end{array}$ & $\begin{array}{l}\square \\
\square\end{array}$ \\
\hline Q4 & What was your level of education? & $\begin{array}{l}\text { 1. No formal education } \\
\text { 2. Alphabet } \\
\text { 3. Primary } \\
\text { 4. Secondary } \\
\text { 5. University }\end{array}$ & $\begin{array}{l}\square \\
\square \\
\square \\
\square \\
\square\end{array}$ \\
\hline Q5 & When did you start working as a motorcycle taxi driver? & 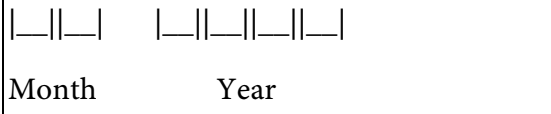 & \\
\hline Q6 & Are you an occasional or regular motorcycle taxi driver? & $\begin{array}{l}\text { 1. Occasional } \\
\text { 2. Regular }\end{array}$ & $\begin{array}{l}\square \\
\square\end{array}$ \\
\hline Q7 & How much do you earn on average per day? & $\mid \_\left\|\_\right\| \_$USD & \\
\hline Q8 & $\begin{array}{l}\text { In your life, which of the following substances } \\
\text { have you ever used? }\end{array}$ & $\begin{array}{l}\text { 1. Alcohol } \\
\text { 2. Tobacco } \\
\text { 3. Tramadol } \\
\text { 4. None }\end{array}$ & $\begin{array}{l}\square \\
\square \\
\square \\
\square\end{array}$ \\
\hline Q9 & $\begin{array}{l}\text { How often have you used the substances } \\
\text { you mentioned (in the last } 30 \text { days)? }\end{array}$ & & \\
\hline Q9a & Alcohol & $\begin{array}{l}\text { 1. Never } \\
\text { 2. Once or twice } \\
\text { 3. Weekly ( } 1-2 \text { times a week) } \\
\text { 4. Monthly } \\
\text { 5. Daily or almost daily (>3 times a week) }\end{array}$ & $\begin{array}{l}\square \\
\square \\
\square \\
\square \\
\square\end{array}$ \\
\hline Q9b & Tobacco & $\begin{array}{l}\text { 1. Never } \\
\text { 2. Once or twice } \\
\text { 3. Weekly (1-2 times a week) } \\
\text { 4. Monthly } \\
\text { 5. Daily or almost daily (>3 times a week) }\end{array}$ & $\begin{array}{l}\square \\
\square \\
\square \\
\square \\
\square\end{array}$ \\
\hline
\end{tabular}




\section{Continued}

\begin{tabular}{|l|l|ll|}
\hline Q9c & Tramadol & $\begin{array}{l}\text { 1. Never } \\
\text { 2. Once or twice } \\
\text { 3. Weekly (1-2 times a week) } \\
\text { Q10 }\end{array}$ & $\begin{array}{l}\text { Have you ever been in a road crash before } \\
\text { being a motorcycle taxi driver?* }\end{array}$ \\
\hline Q11 & $\begin{array}{l}\text { Have you ever been involved in a road crash } \\
\text { after working as a motorcycle taxi driver?* }\end{array}$ & 5. Daily or almost daily (>3 times a week) \\
\hline
\end{tabular}

*A road crash is a collision that occurred on the road between the motorcycle taxi driver while working and any other thing or person and caused injury to at least one of the people involved.

END 